\title{
The Potential Role of Advanced Glycation End Product and iNOS in Chronic Renal Failure-Related Testicular Dysfunction
}

\author{
An Experimental Study \\ İsmail Türker Köksala Mustafa Faruk Usta ${ }^{a}$ Gökhan Akkoyunlu ${ }^{b}$ \\ Behiye Toptaş ${ }^{c}$ Kemal Hakan Gülkesend Tibet Erdoğrua Murat Tuncere \\ Aslı Baykalc Fevzi Ersoy ${ }^{\text {e Ramazan Demir }}{ }^{b}$ Mehmet Baykara ${ }^{a}$ \\ Departments of a Urology, bHistology and Embryology, ${ }^{\mathrm{c} B i o c h e m i s t r y, ~}{ }^{\mathrm{d} B i o s t a t i s t i c s,}$ and e Nephrology, \\ Akdeniz University, Faculty of Medicine, Antalya, Turkey
}

\section{Key Words}

Chronic renal failure $\cdot$ Rat testis - Advanced glycation end products · Inducible nitric oxide synthase • Infertility

\begin{abstract}
Objectives: To investigate the impact of advanced glycation end products (AGEs) and inducible nitric oxide synthase (iNOS) in chronic renal failure (CRF)-associated testicular dysfunction in an experimental model. In additionally, we examined whether different peritoneal dialysis (PD) fluids could contribute to the elevation in AGE level and iNOS expression in the testes. Methods: Adult male Wistar rats, 10 and 12 weeks of age and weighing 200-330 g, were divided into 5 groups. Group 1 served as the control group. In group 2, CRF was induced and a peritoneal catheter was implanted, but the dialysis procedure was not performed until the end of the study. In group 3, CRF was induced and PD was performed with dialysis fluids containing $1.36 \%$ glucose and icodextrin. In group 4, CRF rats received dialysis fluids containing $3.86 \%$ glucose and icodextrin. Finally, an indwelling catheter was implanted and the dialysis procedure was
\end{abstract}

\section{KARGER}

Fax + 41613061234

E-Mail karger@karger.ch

www.karger.com
(C) 2003 S. Karger AG, Basel

0250-8095/03/0235-0361\$19.50/0

Accessible online at:

www. karger.com/ajn performed using dialysis fluids containing $3.86 \%$ glucose and icodextrin (group 5). Chronic PD began 4 weeks after insertion of the catheter. Each morning, this fluid was drained and $20 \mathrm{ml}$ dialysis fluid, containing either 1.36 or $3.86 \%$ glucose, was given intraperitoneally for $4 \mathrm{~h}$ in unanesthetized animals. Each evening, $20 \mathrm{ml}$ icodextrin was given for $10 \mathrm{~h}$. The dialysis procedure was performed for 8 weeks. The AGE level was determined from the 5-hydroxymethyl-2-furaldehyde (5-HMF) content of penis samples and iNOS expression was assessed by immunohistochemistry. Results: The elevation of 5-HMF was significant in the testes from groups 2, 3, 4, and 5 when compared with group 1 . Furthermore, the differences between groups 2 and 4, 3 and 4 , and 4 and 5 were also significant $(p<0.05)$. Immunohistochemical analysis revealed the presence of iNOS predominantly in the Leydig cells. While iNOS staining was significantly lower in group 1 than in other groups, there were also significant differences between groups 2 and 3, 2 and 4, 2 and 5,3 and 5 , and 4 and $5(p<0.05)$. Finally, a significant statistical correlation was found between the 5-HMF and iNOS levels $(r=0.698, p=0.001)$. Conclusions: The present study identifies, for the first time, a potential role
İsmail Türker Köksal, MD

Department of Urology, Akdeniz University, Faculty of Medicine

Dumlupinar Bulvarı, Kampus

TR-07070 Antalya (Turkey)

Tel. +90 24222744 80, Fax +90 24222744 82, E-Mail koksal@med.akdeniz.edu.tr 
of AGE and iNOS in experimental CRF-associated testicular dysfunction. In addition, we found that PD fluids containing glucose contribute to this effect. These results may lead to a better understanding of the pathophysiological pathway in CRF-related testicular dysfunction.

Copyright @ 2003 S. Karger AG, Basel

\section{Introduction}

Chronic renal failure (CRF) is commonly associated with alterations in the reproductive system, manifested by delayed or arrested puberty in childhood and by hypogonadism and infertility in adult life [1-5]. In most cases, these complications rarely normalize with initiation of hemodialysis or peritoneal dialysis (PD) and, in fact, often progress. By comparison a well-functioning renal transplant is much more likely to restore normal sexual activity, although some features of reproduction may remain impaired $[6,7]$. The factors responsible for testicular damage are still under investigation and there is not enough information concerning the underlying pathophysiological mechanism by which CRF can lead to testicular dysfunction.

It has recently been demonstrated that renal failure is associated with a dramatic elevation in kidney tissue and serum advanced glycation end products (AGEs) [8, 9]. These products are the result of the non-enzymatic Maillard reaction linking a protein amino group with glucosederived aldoses or ketoses [10,11]. A striking rise in AGEs was observed in diabetic patients as a result of sustained hyperglycemia $[12,13]$. A greater variety of proteins were thus modified leading to tissue damage through alterations in tissue protein structure and function, stimulation of several cellular responses, or generation of reactive oxygen species [14-16]. In uremia, the rise in AGEs is markedly increased in diabetics and is associated with a variety of tissue disorders, including vascular damage, dyslipidemia, and $\beta_{2}$-microglobulin amyloidosis $[8,9,17$, 18].

It is well established that activation of inducible nitric oxide species (iNOS) occurs through an AGE-dependent mechanism. Under pathological conditions (e.g. varicocele), the testis is characterized by an upregulation of iNOS in Leydig cells that leads to the increased secretion of nitric oxide (NO) [19]. Moreover, O'Bryan et al. [20] concluded that iNOS could play a novel role in modulating different pathophysiological testicular mechanisms. To our knowledge, the relationship between CRF and iNOS via increased AGE production in testicular tissue has not yet been reported. Therefore, the aim of this study was to assess the relationship between AGE levels in testicular tissue and CRF using an experimental model. We also investigated the iNOS expression in rat testicular tissue to determine the possible mechanisms by which AGEs may produce its detrimental effect. Finally, we also examined whether the different PD fluids would affect the elevation in AGE and iNOS expression in testicular tissue.

\section{Material and Methods}

\section{Animals, Surgical Technique and PD}

The study was carried out on 42 adult male Wistar rats, aged between 10 and 12 weeks and weighing 200-330 g. Figure 1 summarizes the surgery and PD protocol performed in this study. CRF was induced by partial nephrectomy under general anesthesia with pentobarbital $50 \mathrm{mg} / \mathrm{kg}$ (i.p.). The left kidney was exposed through a flank incision, and both the upper and lower poles and approximately one third of the remaining cortical tissue of that kidney were excised with the help of bipolar cauterization. During the same session, after mobilizing the adrenal gland, the right kidney was removed after ligation of the renal artery, vein, and ureter. This procedure resulted in a resection of more than $85 \%$ of the renal tissue [21].

Four weeks later, a silicon catheter (Kawasumi venous fistula set, 16-gauge, 35-mm, Lot No. 9718A7) was introduced into the abdominal cavity modifying the protocol described by Miller et al. [22]. The catheter length was determined for each animal, and wedge-shaped smooth holes were made using a sterile surgical blade $3-4 \mathrm{~cm}$ from the distal end of the catheter. The catheter was pushed over a trocar, creating a subcutaneous track ending at the back of the animal's neck. The catheter was closed by a Luer-Lok adaptor. Each morning, under sterile conditions, a catheter was passed through the permanent indwelling catheter, and the peritoneal cavity was rinsed with $20 \mathrm{ml}$ pre-warmed saline. Afterwards, $125 \mathrm{mg} / \mathrm{l}$ ceftazidime and $8 \mathrm{mg} / \mathrm{lgen}$ tamicin were given intraperitoneally. This procedure was continued until the beginning of chronic PD [21].

Chronic PD began 4 weeks after insertion of the catheter. Each morning, the Luer-Lok adaptor was removed and a sterile catheter was passed through the permanent indwelling catheter and rinsed with $20 \mathrm{ml}$ pre-warmed saline. Five minutes later, this fluid was drained and $20 \mathrm{ml}$ dialysis fluid, containing either 1.36 or $3.86 \%$ glucose, was given intraperitoneally for $4 \mathrm{~h}$ in the unanasthetized animal. After the first dwell time of $4 \mathrm{~h}$, the dialysis fluid was drained as much as possible, the peritoneum was rinsed with $20 \mathrm{ml}$ pre-warmed saline, and the Luer-Lok adaptor was closed.

Each evening, after removing the adaptor and rinsing with $20 \mathrm{ml}$ pre-warmed saline, $20 \mathrm{ml}$ icodextrin was given for $10 \mathrm{~h}$, and then it was drained as completely as possible, and the peritoneum was rinsed with pre-warmed saline. Ceftazidime $125 \mathrm{mg} / \mathrm{l}$ and gentamicin $8 \mathrm{mg} / \mathrm{l}$ were added to every dialysate exchange. The dialysis procedure was performed for 8 weeks.

Before chronic PD was begun, the rats were divided into 5 groups. The first group consisted of 6 normal rats and served as the control group (group 1). In 8 rats, CRF was induced and the catheter was implanted, but the dialysis procedure was not performed until the end of the study (group 2). In 10 rats with CRF, chronic PD was performed by dialysis fluids containing $1.36 \%$ glucose and icodextrin 


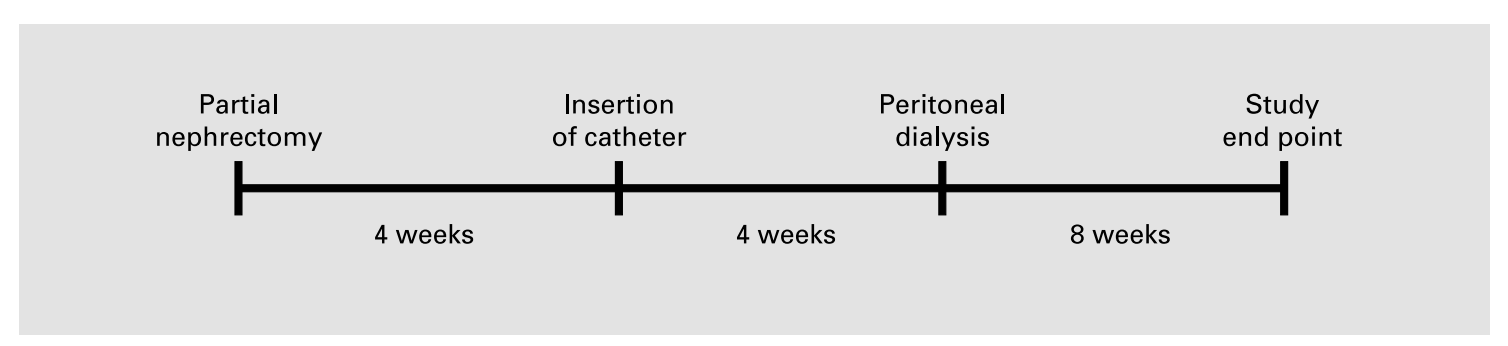

Fig. 1. Surgery and PD protocol performed in animals with chronic renal failure.

(group 3). In group 4, 10 rats with CRF received dialysis fluids containing 3.86\% glucose and icodextrin. Finally, an indwelling catheter was implanted and the dialysis procedure performed using dialysis fluids containing $3.86 \%$ glucose and icodextrin in 8 normal rats (group 5). Each animal was housed in a metabolic cage and the daily fluid and food intake, 24-hour urine volume, and body weight were followed for the entire duration of the experiment. On Tuesdays of each week, blood samples were taken by puncture of the tail vein. The blood samples were assayed for creatinine and urea. Creatinine clearance was monitored every 2 weeks throughout the study period. Animals that did not have a low creatinine clearance before PD were considered as failures.

We chose to evaluate the animals at 16 weeks postoperatively because this point permitted the evaluation of a cohort of animals in which uremia had been produced in a stable homeostatic state.

\section{Tissue Procurement}

At the end of the PD procedure, both testes were delivered into the abdomen and bilateral orchiectomy was performed. The animals were then sacrificed using a lethal overdose of anesthesia. The testicular tissue was stored at $-80^{\circ} \mathrm{C}$ until AGE levels were determined. The testicular samples for iNOS expression were fixed by immersion in Bouin's fixative and routinely processed for paraffin embedding.

\section{Determination of Glycation}

Glycation was determined from the 5-hydroxymethyl-2-furaldehyde (5-HMF) content of the samples using the thiobarbituric acid assay, as described previously [23]. The extracted testis tissues were rinsed with $9 \%$ saline and stored at $-80^{\circ} \mathrm{C}$ until used. Tissues were homogenized with sodium phosphate buffer $(\mathrm{pH} 7.4)$, and the homogenate was used for the determination of glycation. In brief, $1 \mathrm{ml}$ of the $\mathrm{HCl}$ tissue homogenate was boiled in $0.33 \mathrm{M}$ oxalic acid at $100^{\circ} \mathrm{C}$ in a water bath. After $5 \mathrm{~h}$, the hydrolysate was cooled on ice, and cold trichloroacetic acid was added. The resulting precipitates were removed by centrifugation. Aliquots of the supernatants were incubated with thiobarbituric acid at $37^{\circ} \mathrm{C}$. Released 5-HMF was estimated from the absorbances of the samples at $443 \mathrm{~nm}$. Glycation levels are given as nanomoles of 5-HMF per milligram collagen. The collagen level was determined from its hydroxyproline content, as previously described [24]. A 5-HMF standard was used in 6 standard solutions of 5-100 nmol 5-HMF/ml concentrations.

\section{Histopathological and Immunohistochemical Analysis}

For immunohistochemical analysis, 5- to 6- $\mu$ m-thick tissue sections were mounted on poly- $L$-lysine-coated slides. After deparaffi- nation in xylene, sections were rehydrated through a decreasing gradient of ethanol. The sections were then washed for $10 \mathrm{~min}$ in phosphate-buffered saline (PBS, pH 7.2). The endogenous peroxidase activity was inhibited by incubation in methanol containing $3 \%$ $\mathrm{H}_{2} \mathrm{O}_{2}$ for $10 \mathrm{~min}$. After several washes in PBS, the sections were blocked with a universal blocking reagent (BioGenex, San Ramon, Calif., USA) for $10 \mathrm{~min}$ at room temperature. Rabbit polyclonal antiiNOS primary antibody (Santa Cruz Biotechnology Inc., Santa Cruz, Calif., USA) was applied as $2 \mu \mathrm{g} / \mathrm{ml}$ for $1 \mathrm{~h}$ at room temperature. A primary antibody was omitted as negative control. After several washes in PBS, the antibody was detected with an avidin-biotin, horse-radish peroxidase complex using a Universal LSAB+ kit (Dako, Glostrup, Denmark). The sections were rinsed with PBS, and antibody complexes were visualized by incubation with diaminobenzidine tetrahydrochloride (DAB) chromogen (BioGenex). Sections were counterstained with Mayer's hematoxylin (Dako), dehydrated, mounted, and visualized by light microscopy. Tissues from control and experimental groups were processed at the same time. Negative control tests were run without a primary antibody. Immunohistochemical staining was evaluated in 100 Leydig cells in a blinded fashion by 2 examiners and expressed as a positively stained percentage of the cells.

We evaluated the maturation of the seminiferous tubules using Johnsen's score. This scoring system was advocated by Johnsen [25] in 1970 to evaluate the maturation of human seminiferous tubules. It is based on the histologic findings in the testis and especially focuses on the maturity of germ cells in the seminiferous tubules. Johnsen's score for the rat was devised by Lewis-Jones and Kerrigan [26]. The detail of the scoring system is shown in the Appendix. We scored at least 30 tubules per rat in hematoxylin and eosin-stained specimens. For each rat, a mean Johnsen score was calculated.

\section{Statistical Analysis}

Comparisons of 5-HMF levels, iNOS scores and Johnsen's scores among the groups were made by the Kruskal-Wallis and Mann-Whitney U tests, respectively (Statistical Package for Social Sciences, version 10.0.1). The Student's t test was used to compare the body weights, blood creatinine, urea values, and creatinine clearances in the CRF groups (groups 2, 3, and $4 ; n=18$ ) and in the groups without CRF (groups 1 and $5 ; \mathrm{n}=12$ ). A p value of $<0.05$ was considered statistically significant. Finally, Spearman's rho test was used to detect the correlation between the 5-HMF levels and iNOS staining scores. Results are expressed as mean \pm standard deviation. 


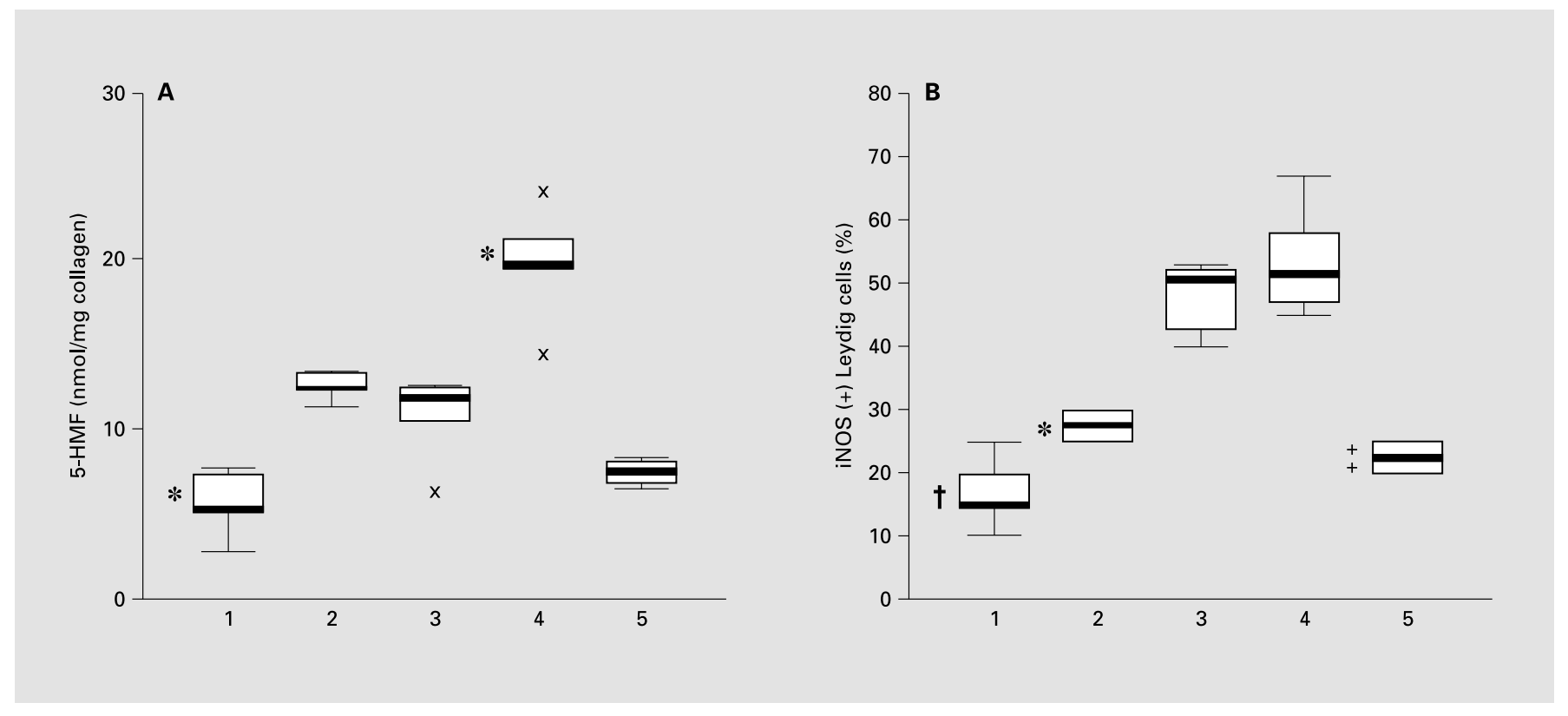

Fig. 2. Box plot graphics of the 5-HMF levels (A) and Leydig cell iNOS staining (B) in th 5 groups. The lines extend between minimum and maximum. The boxes extend between 25 and $75 \%$, and the horizontal lines in the boxes represent the median. $\mathrm{x}=$ Outliers. ${ }^{*}$ Statistically different from other groups. ${ }^{\dagger}$ Different from groups 2,3 and 4. ${ }_{+}^{+}$Different from groups 2, 3 and $4(\mathrm{p}<0.05)$. Group $1=$ Control; group $2=\mathrm{CRF}$, implanted catheter, no dialysis; group $3=\mathrm{CRF}$, chronic PD was performed by dialysis fluids containing $1.36 \%$ glucose and icodextrin; group $4=$ $\mathrm{CRF}$, received dialysis fluids containing $3.86 \%$ glucose and icodextrin; group $5=$ an indwelling catheter was implanted and the dialysis procedure performed using dialysis fluids containing $3.86 \%$ glucose and icodextrin.

\section{Results}

Of the 42 rats in this study, 12 died because of peritoneal trauma, peritonitis attacks, and other problems. Of the rats that died, $4,4,2$, and 2 were in groups $3,4,5$, and 2 , respectively. A significant decrease in the creatinine clearance value was measured in the CRF groups (groups 2,3 , and $4 ; \mathrm{n}=18$ ) compared with control and non-operated groups (groups 1 and $5 ; \mathrm{n}=12$; mean $0.43 \pm 0.11$ versus $2.88 \mathrm{ml} / \mathrm{min}, \mathrm{p}<0.05)$. The mean creatinine clearance value in the CRF group represented $14.8 \%$ of normal, thus we could easily conclude that end-stage renal failure was successfully induced in these rats. All CRF animals had low creatinine clearance values. Although the body weight initially increased $(10 \%)$ in the CRF group the first week after surgery, before PD began, there was a body weight loss $(15 \%)$ in the same group. However, before PD, no statistically significant difference was found in the body weight of the CRF (groups 2, 3, and 4) and non-CRF (groups 1 and 5) animals ( $p>0.05$ ).

\section{Spectrophotometric Analysis for 5-HMF}

The testicular 5-HMF level was $12.57 \pm 0.81,10.97 \pm$ $2.43,19.86 \pm 3.13,7.48 \pm 0.72$, and $5.56 \pm 1.79 \mathrm{nmol} /$ mg collagen in groups $2,3,4,5$, and 1 , respectively (fig. 2). While the elevation in 5-HMF was significant in the testes from groups 2, 3, 4, and 5 compared to group 1, there was also a significant difference for 5-HMF levels between groups 2 and 4,3 and 4 , and 4 and $5(p<0.05)$. In addition, no statistically significant difference was observed between groups 2 and 3 , and 3 and $5(p>0.05)$.

\section{Histopathological and Immunohistochemical Analysis}

In order to determine whether or not testicular histology was similar in our experimental groups the Johnsen scores were investigated. The scores in groups $2,3,4,5$, and 1 were $9.03 \pm 1.16,8.80 \pm 1.07,8.87 \pm 1.20,9.38 \pm$ 0.98 and $9.48 \pm 0.81$, respectively. No statistical differences between the groups were observed $(p>0.05)$.

Immunohistochemical analysis revealed the presence of iNOS predominantly in the Leydig cells (fig. 3). Immunohistochemical iNOS staining in Leydig cells was $27.5 \pm$ 

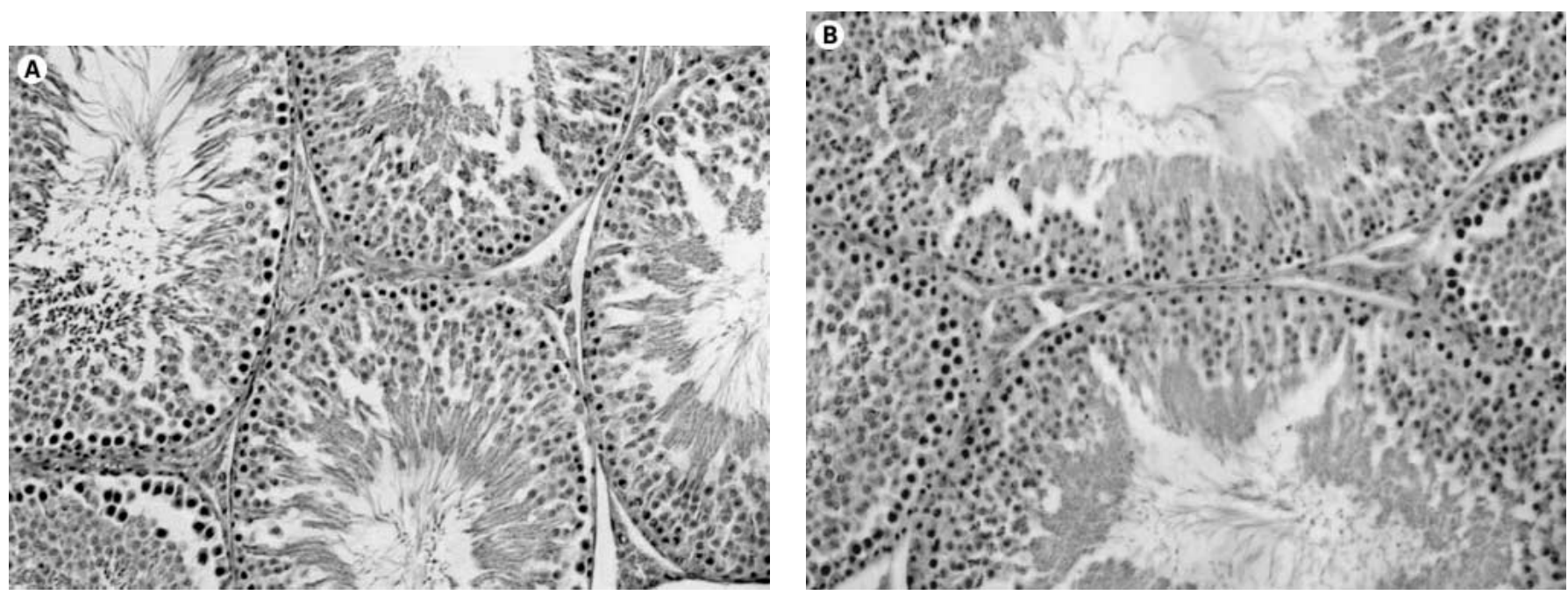

Fig. 3. A The control group (group 1) testis showed a normal architecture of the seminiferous epithelia and interstitial area with a specific iNOS immunoreactivity in Leydig cell cytoplasms. B The most intense iNOS immunoreactivity was observed in the cytoplasm of Leydig cells, in group 4 with CRF and received dialysis fluids containing $3.86 \%$ glucose and icodextrin. C Normal spermatogenic maturation, void of any immunoreactivity was observed in the negative control section. All figures are original magnifications: $\times 20$.

$2.73,48.16 \pm 5.34,53.33 \pm 8.11,22.5 \pm 2.73$ and 16.66 \pm 5.16 in groups $2,3,4,5$, and 1 , respectively (fig. 2). iNOS staining was significantly lower in group 1 than in groups 2,3 , and $4(\mathrm{p}<0.05)$. In addition, the differences between groups 2 and 3,2 and 4, 2 and 5, 3 and 5, and 4 and 5 were statistically significant $(\mathrm{p}<0.05)$. No statistically significant difference was observed between groups 3 and 4 , and 1 and $5(\mathrm{p}>0.05)$.

Finally, a significant statistical correlation was found between the iNOS and 5-HMF levels $(\mathrm{r}=0.698, \mathrm{p}=$ $0.001)$.

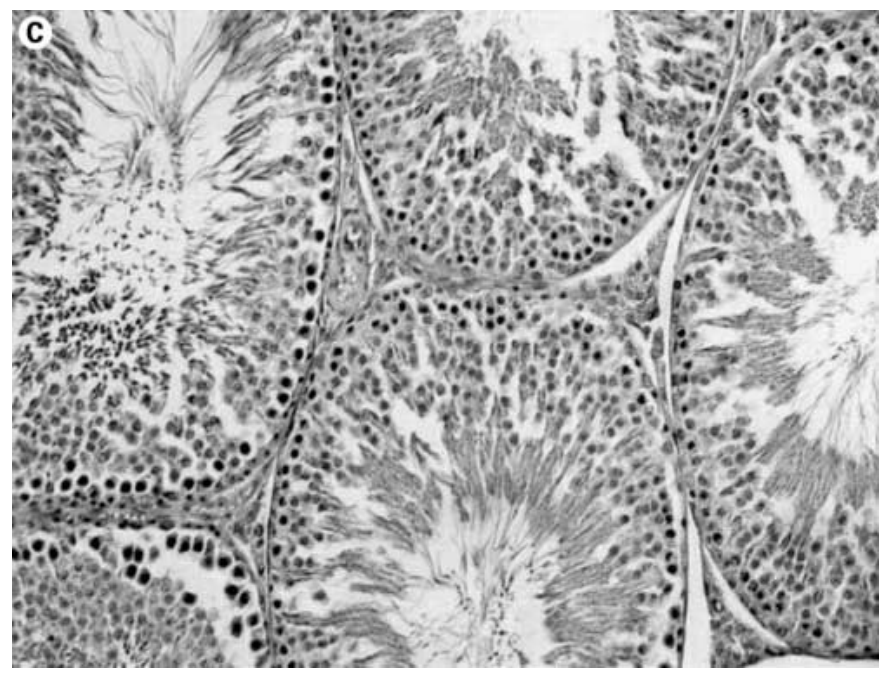

\section{Discussion}

Renal failure is associated with the retention of a variety of toxic compounds responsible for the uremic syndrome. The development of renal replacement therapy, and especially dialysis, has led to the identification of a series of complications associated with long-term CRF. One of the most encountered complications is CRF-associated testicular dysfunction, which often causes infertility [1-5]. The exact pathophysiological mechanism involved in CRF-induced testicular damage is not fully understood. Histological changes in the testis, including evidence of decreased spermatogenic activity with the greatest changes in the hormonally dependent later stages of spermatogenesis has been reported [6]. However, Adachi et al. [27] recently demonstrated that testicular histol-

Am J Nephrol 2003;23:361-368 365

Advanced Glycation End Product and

iNOS in Chronic Renal Failure-Related

Testicular Dysfunction 
ogy is not influenced by CRF in rats. In the present study, there was no statistically significant correlation in Johnsen's scores, which represent the testicular histology between the CRF-induced and control rats $(p>0.05)$.

The accumulation of AGEs in the human body has been implicated in the complications of diabetes, aging, and renal failure [8-12, 28]. Reduced sugars, such as aldoses and ketoses, react non-enzymatically with primary amino groups on proteins to form a glycated residue called Amadori products. Amadori products undergo a series of dehydration and fragmentation reactions to form the stable covalent adducts, namely AGEs [10, 11]. Although the effect of CRF on testicular function has been reported, the relationship between CRF and AGEs with regard to testicular CRF-induced pathology has not yet been investigated. Therefore, we studied the possible relationship between AGE levels in testicular tissue and CRF using an experimental model and found that AGE levels were significantly higher in the groups with uremia than in the control group.

To determine AGE, several methods were considered, including binding and chemical methods. Measurement of 5-HMF is one of the chemical methods [29, 30]. We recently studied a glycation end product, 5-HMF, in rat penile tissue in which uremia had been produced [21]. In this study, we found a significant increase in the 5-HMF levels in the uremic penile tissue of the rat. Taking this into account, in the present study we investigated the testicular 5-HMF levels in rats with CRF.

Commercially available PD solutions contain supraphysiological concentrations of glucose. The chronic contact of glucose containing dialysate and proteins results in the deposition of AGEs on peritoneal tissues in patients treated by PD [31, 32]. Furthermore, heat sterilization of PD fluids degrades glucose into a variety of glucose degradation products that may induce AGEs in several tissues, and may lead to detrimental effects in the peripheral vasculature [33]. According to these findings, we investigated whether different PD fluids with varying glucose concentrations could affect the elevation in AGEs in testicular tissue. We found that the 5-HMF testicular levels in group 4 with CRF, treated with $3.86 \%$ glucose PD fluid, were significantly higher than in group 3 with CRF, treated with $1.36 \%$ glucose PD fluid $(\mathrm{p}<0.05)$. Those data suggest that a high glucose concentration in PD lead to increased 5-HMF levels in testicular tissue.

The interaction between AGEs and iNOS has widely been accepted [34]. In addition, it is well defined that NO has a crucial impact on testicular dysfunction. In vitro data have indicated that NO inhibits Leydig cell testoster- one production, suggesting that NO may play a role in the suppression of steroidogenesis and spermatogenic function [35-38]. Leydig cells and testicular vasculature are physiological sites of NO production [39]. Therefore, we also investigated the iNOS expression in the same rat groups and found that the iNOS expression is significantly higher in the groups with uremia than in the control group. Moreover, we also analyzed the impact of different PD fluids on testicular iNOS activity. The iNOS expression in group 4 with CRF, treated with $3.86 \%$ glucose, and group 3 with CRF, treated with $1.36 \%$ glucose fluid, was significantly higher than in groups 1,2 , and 5 . Our results also indicate that immunolocalization of iNOS is predominantly in the Leydig cells. These data suggest that CRF leads to increased Leydig cell iNOS expression and elevated AGE levels.

Moreover, we found that there was a significant statistical correlation between the 5-HMF levels and iNOS expression in our study.

\section{Conclusions}

We investigated the potential role of AGEs and iNOS in CRF-associated testicular dysfunction, using an experimental model. Our results show that AGE and iNOS testicular levels are significantly increased in CRF-induced rats. In addition, we found that different PD fluids containing high glucose contribute to the elevation in AGE and iNOS levels in the same animal groups. These results better our understanding of the underlying pathological consequences of CRF-related testicular pathology.

\section{Acknowledgements}

The authors would like to thank Ryan Chatelain (Tulane University School of Medicine, New Orleans, La., USA) for the preparation of the manuscript.

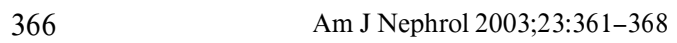

Köksal et al. 


\section{Appendix}

Johnsen's Score for the Rat

10 Fully mature spermatogenesis is observed (mature hooked spermatozoa with dense nuclear chromatin lying within tubular lumen). Pyknotic bodies are present.

9 Same criteria as for 10 , but the germinal epithelium shows marked sloughing or obliteration of the lumen.

8 More than 10 immature spermatozoa, with dense nuclear staining and hooked heads are observed; the majority is peripherally placed within the tubule. Pyknotic bodies are sometimes present.

7 Less than 10 spermatozoa are observed. The majority of cells are mature spermatids and are peripherally placed with less dense nuclear staining. No pyknotic bodies present.
6 Mid-phase spermatids, with pale chromatin and narrow oval heads are observed; they are radially arranged. No pyknotic bodies present.

5 Immature spermatids, randomly arranged throughout the tubule are observed; each has a round nucleus with pale chromatin. No pyknotic bodies present.

4 Only a few spermatocytes (less than 5) are observed and no spermatids or spermatozoa.

3 Spermatogonia are the only germ cells present.

2 No germ cells are present, but Sertoli cells are.

1 No cells are present in the tubular section.

\section{References}

1 Schaefer F, Mehls O: Endocrine and growth disorders; in Barrant TM, Avner ED, Harmon WE (eds): Pediatric Nephrology, ed 4. Baltimore, William \& Wilkins, 1998, pp 1197 1420 .

2 Handelsman DJ: Hypothalamic-pituitary gonadal dysfunction in renal failure, dialysis and renal transplantation. Endocr Rev 1985;6:151182.

3 Schmidt RJ, Holley JL: Fertility and contraception in end-stage renal disease. Adv Ren Replace Ther 1998;5:38-44.

4 Prem AR, Punekar SV, Kalpana M, et al: Male reproductive function in uraemia: Efficacy of haemodialysis and renal transplantation. $\mathrm{Br} \mathrm{J}$ Urol 1996;78:635-638.

5 Handelsman DJ: Hypothalamic-pituitary gonadal dysfunction in renal failure, dialysis and renal transplantation. Endocr Rev 1985;6:151182.

6 Palmer BF: Sexual dysfunction in uremia. J Am Soc Nephrol 1999;10:1381-1388.

7 Holdsworth SR, de Kretser DM, Atkins RC: A comparison of hemodialysis and transplantation in reversing the uremic disturbance of male reproductive function. Clin Nephrol 1978;10:146-150

8 Miyata T, Maeda K, Kurokawa K, et al: Oxidation conspires with glycation to generate noxious advanced glycation end products in renal failure. Nephrol Dial Transplant 1997;12:255258.

9 Miyata T, Taneda S, Kawai R, et al: Identification of pentosidine as a native structure for advanced glycation end products in beta-2microglobulin-containing amyloid fibrils in patients with dialysis-related amyloidosis. Proc Natl Acad Sci USA 1996;3:2353-2358.

10 Brownlee M, Cerami A, Vlassara H: Advanced glycosylation end products in tissue and the biochemical basis of diabetic complications. $\mathrm{N}$ Engl J Med 1988;19:318:1315-1321.
11 Fu MX, Wells-Knecht KJ, Blackledge JA, et al: Glycation, glycoxidation, and cross-linking of collagen by glucose. Kinetics, mechanisms, and inhibition of late stages of the Maillard reaction. Diabetes 1994;43:676-683.

12 Dyer DG, Dunn JA, Thorpe SR, et al: Accumulation of Maillard reaction products in skin collagen in diabetes and aging. J Clin Invest 1993; 91:2463-2469.

13 McCance DR, Dyer DG, Dunn JA, et al: Maillard reaction products and their relation to complications in insulin-dependent diabetes mellitus. J Clin Invest 1993;91:2470-2478.

14 Yeung JH: Effects of glycerol-induced acute renal failure on tissue glutathione and glutathione-dependent enzymes in the rat. Methods Find Exp Clin Pharmacol 1991;13:23-28.

15 Witko-Sarsat V, Friedlander M, CapeillereBlandin C, et al: Advanced oxidation protein products as a novel marker of oxidative stress in uremia. Kidney Int 1996;49:1304-1313.

16 Miyata T, Wada Y, Cai Z, et al: Implication of an increased oxidative stress in the formation of advanced glycation end products in patients with end-stage renal failure. Kidney Int 1997; 51:1170-1181.

17 Miyata T, Iida Y, Horie K, et al: Pathophysiology of advanced glycation end-products in renal failure. Nephrol Dial Transplant 1996; 11(suppl 5):27-30.

18 Miyata T, Sugiyama S, Saito A, et al: Reactive carbonyl compounds related uremic toxicity ('carbonyl stress'). Kidney Int Suppl 2001;78: 25-31.

19 Santoro G, Romeo C, Impellizzeri P, et al: Nitric oxide synthase patterns in normal and varicocele testis in adolescents. BJU Int 2001;88: 967-973.

20 O'Bryan MK, Schlatt S, Gerdprasert O, et al: Inducible nitric oxide synthase in the rat testis: evidence for potential roles in both normal function and inflammation-mediated infertility. Biol Reprod 2000;63:1285-1293.
21 Usta MF, Tuncer M, Baykal A, et al: Impact of chronic renal failure and peritoneal dialysis fluids on advanced glycation end product and iNOS levels in penile tissue: An experimental study. Urology 2002;59:953-957.

22 Miller TE, Findon G, Rowe L: Characterization of an animal model of continuous peritoneal dialysis in chronic renal impairment. Clin Nephrol 1992;37:42-47.

23 Rosenberg H, Modrak JB, Hassing JM, et al: Glycosylated collagen. Biochem Biophys Res Commun 1979;91:498-501.

24 Baykal-Erkilic A, Erkilic M, Ozben T: The effects of streptozocin-induced diabetes on renal plasma flow. Exp Clin Endocrinol Diabetes 1995; 103:367-372.

25 Johnsen SG: Testicular biopsy score count: a method for registration of spermatogenesis in human testes: Normal values and results in 335 hypogonadal males. Hormones 1970;1:2-25.

26 Lewis-Jones DI, Kerrigan DD: A modified Johnsen's count for evaluation of spermatogenesis in the rat. IRCS Med Sci 1985;13:510_ 511.

27 Adachi Y, Sasagawa I, Tateno T, et al: Testicular histology in experimental uremic rats. Arch Androl 1998;41:51-55.

28 Sell DR, Nelson JF, Monnier VM: Effect of chronic aminoguanidine treatment on age-related glycation, glycoxidation, and collagen cross-linking in the Fischer 344 rat. J Gerontol A Biol Sci Med Sci 2001;56:B405-B411.

29 Beisswenger PJ, Healy JC, Shultz EK: Glycosylated serum proteins and glycosylated hemoglobin in the assessment of glycemic control in insulin-dependent and non-insulin-dependent diabetes mellitus. Metabolism 1993;42:989992.

30 Black CT, Hennessey PJ, Ford EG, et al: Protein glycosylation and collagen metabolism in normal and diabetic rats. J Surg Res 1989;47: 200-202. 
31 Friedlander MA, Wu YC, Elgawish A, et al: Early and advanced glycosylation end products. Kinetics of formation and clearance in peritoneal dialysis. J Clin Invest 1996;97:728735.

32 Friedlander MA, Wu YC, Schulak JA, et al: Influence of dialysis modality on plasma and tissue concentrations of pentosidine in patients with end-stage renal disease. Am J Kidney Dis 1995;25:445-451.

33 Kjellstrand P, Martinson E, Wieslander A, et al: Development of toxic degradation products during heat sterilization of glucose-containing fluids for peritoneal dialysis: Influence of time and temperature. Perit Dial Int 1995;15:2632 .
34 Bucala R, Tracey KJ, Cerami A: Advanced glycosylation products quench nitric oxide and mediate defective endothelium-dependent vasodilatation in experimental diabetes. J Clin Invest 1991;87:432-438.

35 Middendorff R, Muller D, Wichers S, et al: Evidence for production and functional activity of nitric oxide in seminiferous tubules and blood vessels of the human testis. J Clin Endocrinol Metab 1997;82:4154-4161.
36 Del Punta K, Charreau EH, Pignataro OP: Nitric oxide inhibits Leydig cell steroidogenesis. Endocrinology 1996;137:5337-5343.

37 Tatsumi N, Fujisawa M, Kanzaki M, et al: Nitric oxide production by cultured rat Leydig cells. Endocrinology 1997;138:994-998.

38 Pomerantz DK, Pitelka V: Nitric oxide is a mediator of the inhibitory effect of activated macrophages on production of androgen by the Leydig cell of the mouse. Endocrinology 1998; 139:922-931.

39 Fujisawa M, Yamanaka $\mathrm{K}$, Tanaka $\mathrm{H}$, et al: Expression of endothelial nitric oxide synthase in the Sertoli cells of men with infertility of various causes. BJU Int 2001;87:85-88. 